\title{
Fabrication of p-type Transparent (CuZn)O Thin Films by the Electrochemical Deposition Method
}

\author{
Mansoureh Keikhaei*, Masaya Ichimura \\ Department of Engineering Physics, Electronics and Mechanics, Nagoya Institute of Technology, \\ Gokiso, Showa, Nagoya 466-8555, Japan \\ *E-Mail: keykhaei@,gmail.com, ichimura.masaya@nitech.ac.jp
}

doi: $10.20964 / 2020.01 .28$

Received: 3 September 2019 / Accepted: 24 October 2019 / Published: 30 November 2019

Copper zinc oxide $(\mathrm{CuZn}) \mathrm{O}$ thin films were fabricated on indium tin oxide-coated glass substrates using the cathodic electrochemical deposition method under various conditions. These included different temperatures, deposition times, and potentials. The deposition solution contained $1 \mathrm{mM}$ $\mathrm{Cu}\left(\mathrm{NO}_{3}\right)_{2}$ and various concentrations of $\mathrm{Zn}\left(\mathrm{NO}_{3}\right)_{2}$. X-ray diffraction demonstrated that wurtzite structure for films deposited at $60^{\circ} \mathrm{C}$, whereas samples that deposited at room temperature were amorphous. In the visible region, the samples exhibited high optical transmission, i.e., larger than $65 \%$. Conductivity was found to be p-type by photoelectrochemical characterizations for the samples fabricated at room temperature. In contrast, the films fabricated at $60^{\circ} \mathrm{C}$ were $\mathrm{n}$-type or close to intrinsic.

Keywords: electrochemical deposition, thin films, transparent, $(\mathrm{CuZn}) \mathrm{O}$

\section{FULL TEXT}

(C) 2020 The Authors. Published by ESG (www.electrochemsci.org). This article is an open access article distributed under the terms and conditions of the Creative Commons Attribution license (http://creativecommons.org/licenses/by/4.0/). 